\title{
Retraction Note: Effect of Perioperative Intravenous Lignocaine Infusion on Haemodynamic Responses and postoperative Analgesia in Laparoscopic Cholecystectomy Surgeries
}

\author{
Krishna Murthy TK ${ }^{1}$ and Vinay Kumar PV ${ }^{1,{ }^{*}}$ \\ ${ }^{1}$ Department of Anaesthesia, Sri Siddhartha Medical College, Tumkur \\ "Corresponding author: Department of Anaesthesia, Sri Siddhartha Medical College, Tumkur Email: drvinay81@gmail.com
}

Received 2021 August 22; Accepted 2021 October 22.

This retracts the article "Retracted Article: Effect of Perioperative Intravenous Lignocaine Infusion on Haemodynamic Responses and postoperative Analgesia in Laparoscopic Cholecystectomy Surgeries".

I, as the corresponding author of the mentioned article [Anesth Pain Med. 2018; 8(2): e63490] and on behalf of all authors, state that because of conflict of interest among the authors plus due to the fact that tables in article were taken from a student thesis (plagiarized), decided to retract our article.

Kind Regards,
Kumar PV, Vinay
Corresponding author 